\title{
Comparative genomics of bacteria in the genus Providencia isolated from wild Drosophila melanogaster
}

\author{
Madeline R Galac and Brian P Lazzaro*
}

\begin{abstract}
Background: Comparative genomics can be an initial step in finding the genetic basis for phenotypic differences among bacterial strains and species. Bacteria belonging to the genus Providencia have been isolated from numerous and varied environments. We sequenced, annotated and compared draft genomes of $P$. rettgeri, P. sneebia, P. alcalifaciens, and P. burhodogranariea. These bacterial species that were all originally isolated as infections of wild Drosophila melanogaster and have been previously shown to vary in virulence to experimentally infected flies.
\end{abstract}

Results: We found that these Providencia species share a large core genome, but also possess distinct sets of genes that are unique to each isolate. We compared the genomes of these isolates to draft genomes of four Providencia isolated from the human gut and found that the core genome size does not substantially change upon inclusion of the human isolates. We found many adhesion related genes among those genes that were unique to each genome. We also found that each isolate has at least one type 3 secretion system (T3SS), a known virulence factor, though not all identified T3SS belong to the same family nor are they in syntenic genomic locations.

Conclusions: The Providencia species examined here are characterized by high degree of genomic similarity which will likely extend to other species and isolates within this genus. The presence of T3SS islands in all of the genomes reveal that their presence is not sufficient to indicate virulence towards $D$. melanogaster, since some of the T3SS-bearing isolates are known to cause little mortality. The variation in adhesion genes and the presence of T3SSS indicates that host cell adhesion is likely an important aspect of Providencia virulence.

Keywords: Providencia, Drosophila melanogaster, Whole genome comparison, Host-pathogen interactions, Genomics, Providencia rettgeri, Providencia sneebia, Providencia alcalifaciens, Providencia burhodogranariea

\section{Background}

Providencia are ubiquitous Gram-negative bacteria in the family Enterobacteriaceae that are often opportunistic pathogens. They are commonly found to cause traveler's diarrhea and urinary tract infections in humans but have also been isolated from more severe human infections such as meningitis [1-4]. They have been identified as part of the normal human gut flora and the genomes of some strains have been sequenced as part of the Human Microbiome Project [5]. Additionally, Providencia have been associated with numerous animals

\footnotetext{
* Correspondence: bplazzaro@cornell.edu

Field of Genetics and Development, 3125 Comstock Hall, Cornell University,
} Ithaca, NY 14853, USA

\section{() Biomed Central

(c) 2012 Galac and Lazzaro; licensee BioMed Central Ltd. This is an Open Access article distributed under the terms of the Creative Commons Attribution License (http://creativecommons.org/licenses/by/2.0), which permits unrestricted use, distribution, and reproduction in any medium, provided the original work is properly cited. worldwide, including isolation from penguin feces in German zoos [6], sea turtles in the Mediterranean [7], shark mouths in Brazil [8], entomopathogenic nematodes globally [9], and snakes from Vietnam [10]. Providencia have also been found in association with insects such as blowflies [11], stable flies [12], Mexican fruit flies [13], and house flies [14]. Providencia have also been found in the guts and external environment of Drosophila melanogaster $[15,16]$.

Providencia strains have been additionally isolated as infectious agents of $D$. melanogaster and have been shown to have distinct phenotypes including varied virulence towards D. melanogaster $[17,18]$. Two species, Providencia sneebia and Providencia alcalifaciens, were found to be highly virulent, causing $90-100 \%$ mortality in 
infected flies. Infections with the other two, Providencia rettgeri and Providencia burhodogranariea, caused only moderate mortality, with $30-40 \%$ of infected flies succumbing to the infection [18]. The more lethal bacteria tended to proliferate to higher densities in the fly, and triggered greater expression of antibacterial immune genes, with the exception of $P$. sneebia, which did not induce substantial antimicrobial peptide gene expression despite rapid and lethal proliferation [18].

In the present work, we have sequenced, annotated, and compared the draft genomes of the four species isolated from infections in wild $D$. melanogaster: $P$. sneebia, $P$. rettgeri, $P$. burhodogranariea and $P$. alcalifaciens. We compared our sequences to draft genomes of four sequenced species of Providencia isolated from the human gut [5]. We sought specifically to identify the core Providencia genome and accessory genes, to establish which genes may be evolving under positive selection, and to annotate differences in gene content that contribute to physiological differences among the isolates.

\section{Methods}

\section{Bacteria strains sequenced}

The four bacteria strains that were sequenced in this study were isolated from the hemolymph of wild caught Drosophila melanogaster [18]. They are the Providencia sneebia Type strain (DSM 19967) [GenBank:AKKN 00000000], Providencia rettgeri strain Dmel1 [GenBank: AJSB00000000], Providencia alcalifaciens strain Dmel2 [GenBank:AKKM00000000], and Providencia burhodogranariea Type strain (DSM 19968) [Genbank:AKKL 00000000]. The versions described in this paper are the first versions, XXXX01000000.

\section{Genome sequencing and assembly of $P$. rettgeri and $P$. sneebia}

Bacterial DNA was extracted using Puregene DNA Purification Kit (Gentra Systems Inc., Minneapolis, $\mathrm{MN}$ ) according to the manufacturer's directions for Gram-negative bacteria. The DNA was then sequenced using FLX Roche/454 Sequencing Technology at Cornell University's Life Science Core Laboratory Center in Ithaca, NY.

$P$. sneebia and $P$. rettgeri were sequenced with approximately 500,000 reads of an average length of 250 $\mathrm{bp}$, providing about 30X coverage for each genome. The sequences for each species were obtained from separate full-plate sequencing runs and independently assembled using the LaserGene SeqMan (version 8) software with the manufacturer's recommended parameters (Additional file 1: Figure S1). An additional 180,000 reads were obtained from a 454 sequencing plate on which the DNA from $P$. sneebia and $P$. rettgeri was separated by a rubber gasket. During the sequencing process, this gasket leaked allowing a very small amount of reciprocal contamination. We did not want to discard these sequences entirely, but we also wanted to avoid any contaminating reads fouling our assemblies. Therefore our second assembly step was to assemble the reads from the half-plate to those contigs initially assembled with the uncontaminated full-plate reads using SeqMan (Additional file 1: Figure S1). From this second step of assembly, we retained: (1) contigs that contained halfplate reads assembled to full-plate contigs, increasing the depth of those contigs, (2) contigs in which halfplate reads bridged previously separate contigs from the full-plate assemblies, allowing them to be stitched together, and (3) novel contigs containing only half-plate reads but with a coverage depth of 30X or greater. Contaminating sequences in the half-plate reads would presumably fail to map to full-plate assemblies or would result in low-coverage contigs, so we infer that the small number of molecules that leaked through the gasket have been effectively discarded. After the second round of assembly, the P. sneebia genome was mapped into 72 contigs and the $P$. rettgeri genome was mapped into 71 contigs.

As we were annotating the P. sneebia and P. rettgeri genome sequences (see "Annotation methods" section below), we noticed several instances of sequential open reading frames (ORFs) that were annotated with the same predicted function and whose combined length equaled the size of genes with the same functional annotation in other bacteria. Closer inspection revealed that these instances were generally due to a stop codon or frameshift mutation that interrupted the ORF, causing it to be annotated as two genes with identical function. These inferred mutations tended to happen after short homopolymer runs. Individual reads varied in the lengths of these homopolymer sequences, and the contig assembly often did not reflect the most common sequence length among the reads. It is a known problem that Roche/454 Sequencing often results in errors in homopolymer run lengths [19]. To improve the accuracy of inferred homopolymer lengths, we re-aligned all of the Roche/454 sequencing reads to our assembled reference sequences using the program BWA [20] (Additional file 1: Figure S1). The consensus homopolymer length from the BWA alignment was used to fix the assembled contigs before any further analysis was performed. This correction improved our gene annotations by eliminating sequencing errors that interrupted ORFs.

We aimed to improve the assemblies of our P. sneebia and $P$. rettgeri genomes by joining contigs through PCR followed by direct Sanger sequencing. However, the order and orientation of the contigs was unknown. We hypothesized that there would be synteny among the 
genomes of Providencia species and isolates as well as species in the closely related genus Proteus, which we could use to predict the order and orientations of the contigs in our assemblies (Additional file 1: Figure S1). We used MUMmer (version 3.22) [21] to compare $P$. sneebia and $P$. rettgeri to the draft genomes of Providencia rettgeri DSM 1131 (283 contigs) [GenBank:ACCI00000000], Providencia alcalifaciens DSM 30120 (79 contigs) [GenBank:ABXW00000000], Providencia stuartii ATCC 25827 (120 contigs) [GenBank: ABJD00000000], and Providencia rustigianii DSM 4541 (127 contigs) [GenBank:ABXV00000000] as well as the completed genome of Proteus mirabilis strain HI4320 [GenBank:NC_010554.1]. Where two of our P. rettgeri or P. sneebia contigs had similarity to a single contig of one of the other genome sequences, we designed PCR primers to amplify across the inferred gap. Successful amplifications were sequenced by primer walking and the resultant sequences were used to bridge contigs in the assemblies. PCR and sequencing methods are described below in the "PCR and Sanger sequencing methods" section. We found that designing the primers inset about 900 bp from the contig breakpoints helped to ensure specificity in amplification, especially because repetitive sequences in the genome can be the cause of contig breaks in genome assemblies. Using this method, we reduced the number of contigs in the P. sneebia assembly from 72 to 67 and in the $P$. rettgeri assembly from 71 to 64 .

To further connect the P. sneebia and P. rettgeri assemblies, we contracted the MapIt optical mapping service from OpGen, Inc. (Gaithersburg, MD) and analyzed the resulting data using their program MapSolver (version 2.1.1) (Additional file 1: Figure S1). An in silico digestion of our contigs allowed them to be oriented onto an in vitro restriction digestion map of each bacterium's physical genome. This ordered and oriented the contigs and allowed us to identify those contigs that comprised the majority of each genome. We used the optical map to identify physically consecutive contigs, then designed primers for PCR and Sanger sequencing to close most of the remaining gaps. The optical map also indicated a small number of computational misassemblies and allowed them to be fixed. After optical mapping and final gap closing, our draft genome sequences were assembled into 14 contigs for P. sneebia and 9 contigs for $P$. rettgeri.

\section{Genome sequencing and assembly of $P$. alcalifaciens and $P$. burhodogranariea}

$P$. alcalifaciens and P. burhodogranariea were sequenced by paired-end 454 sequencing. Libraries were constructed for each bacterium with an approximately $3 \mathrm{~kb}$ insert size, and roughly 1 million paired-end sequence reads of an average length of 250 bases were collected. The pairedend reads were assembled using Roche/454's Newbler Assembler (version 2.5.3), which resulted in 15 scaffolds for $P$. alcalifaciens and 8 scaffolds for $P$. burhodogranar$i e a$, sequenced to roughly $35 \mathrm{X}$ coverage.

\section{PCR and Sanger sequencing methods}

PCR primers for gap closing were designed either using Primer3 [22] or with a primer design function within SeqMan. PCRs were performed using a genomic DNA template with a final concentration of $1.2 \mathrm{ng} / \mu \mathrm{l}$ in each PCR reaction volume.

When the size of the expected product was unknown or was expected to be less than $5 \mathrm{~kb}$, the PCR was done with Taq polymerase (New England Biolabs, Beverly, MA) with an annealing temperature gradient ranging from $2^{\circ} \mathrm{C}$ higher to $2^{\circ} \mathrm{C}$ lower than the melting temperature of the primers. PCR cycling parameters were as follows: (1) 2 minutes at $95^{\circ} \mathrm{C}$, (2) 30 seconds at $95^{\circ} \mathrm{C}$, (3) 30 seconds at annealing temperature gradient, (4) 1 minute at $72^{\circ} \mathrm{C}$, (5) repeat steps $2-4$ for 34 more cycles, (6) 5 minutes at $72^{\circ} \mathrm{C} .3 .5 \mu \mathrm{l}$ of each PCR product was prepared for sequencing by treatment with 5 units of Exonuclease I (USB Corp., Cleveland, $\mathrm{OH}$ ) and 0.5 units of shrimp alkaline phosphatase (USB Corp., Cleveland, $\mathrm{OH}$ ) at $37^{\circ} \mathrm{C}$ for one hour before heat-killing the enzymes at $65^{\circ} \mathrm{C}$ for 15 minutes. PCR products were then directly sequenced using $A B I$ BigDye Terminator (Applied Biosystems, Foster City, CA) according to the manufacturer's directions.

PCR for products with an expected size greater than $5 \mathrm{~kb}$ was done using high fidelity iProof polymerase (Bio-Rad, Hercules, CA). Annealing temperatures and extension times were determined using manufacturer's suggested methods. The PCR cycling parameters were: (1) 30 seconds at $98^{\circ} \mathrm{C}$, (2) 7 seconds at $98^{\circ} \mathrm{C}$, (3) 20 seconds at appropriate annealing temperature, (4) appropriate extension time at $72^{\circ} \mathrm{C}$, (5) repeat steps $2-4$ for 29 more cycles, (6) 7 minutes at $72^{\circ} \mathrm{C}$. Products were prepared for sequencing with $\mathrm{PCR}$ purification clean up columns (Invitrogen, Calsbad, CA) before being sequenced directly.

\section{Annotation methods}

Genomic open reading frames were determined and annotated using the RAST Server (version 4) [23]. Gene ontology terms (GO terms) were assigned to the ORFs identified by RAST using Blast2GO (version 2.5) [24]. Fisher's Exact Test for enriched GO categories was done within Blast2GO using a $p$-value cut off of 0.05 after adjusting for a standard false discovery rate (FDR) of 0.05 for multiple testing. 


\section{Plasmid identifications and analysis}

The circular DNA structure of plasmids means that they will appear to be arbitrary broken when forming linear contigs during assembly of sequencing reads. We tested all potential plasmid contigs for a circular physical structure by designing PCR primers approximately 500 bases from the ends of the contig facing outward off each end of the contig. This primer design means that a product would be formed only if the ends of the contig were connected in the physical DNA. Any PCR product amplified from such primers was then sequenced with Sanger sequencing to confirm that the sequence supported a circular physical arrangement of the sequence. PCR reactions and Sanger sequencing was done as described above in "PCR and Sanger sequencing methods".

Putative plasmids were identified in multiple ways. We speculated that one $P$. rettgeri contig might be a plasmid because it had substantially higher depth of coverage than other contigs, and when we compared the contig to itself using MUMmer, we found that it was composed of the same sequence repeated multiple times. We hypothesized that the contig might actually represent a completely sequenced, high copy number plasmid, and that the circular shape of the physical DNA sequence was resulting in a tandem repeat of the sequence in the in silico assembly. PCR and Sanger sequencing confirmed that this contig is a plasmid.

To more systematically assess whether contigs from the assemblies were plasmids, we looked for contigs with identical sequence present at both ends. We hypothesized that the arbitrary break point of the physical circular structure to form a linear contig could result in identical sequence at each end of the contig. We used MUMmer to compare contigs to themselves. For $P$. sneebia and $P$. rettgeri, we examined all contigs which did not align to the optical map since we do not expect plasmids to map to the chromosomal genome. We identified three P. sneebia plasmids using this method, all of which were confirmed by PCR and Sanger sequencing. We identified no additional $P$. rettgeri contigs as putative plasmids using this approach. For $P$. alcalifaciens and $P$. burhodogranariea, we examined every scaffold smaller than $6 \mathrm{~kb}$ in length, but none contained the same sequence at both ends of the contig. It should be noted that this method may result in an underestimation of plasmids since it will not detect plasmids that assemble into multiple contigs.

When examining the synteny of the genomes (see "Synteny and regional comparisons" section below), we noticed that some of the contigs of $P$. alcalifaciens had no similarity to sequences in any of the other genomes. We hypothesized that these contigs could be plasmids that are unique to $P$. alcalifaciens. We tested four contigs by PCR and Sanger sequencing. One contig was confirmed to be a plasmid while the other three did not produce PCR products and therefore showed no evidence of being plasmids.

All putative plasmids were compared to each other using MUMmer. In order to determine whether our confirmed plasmids or previously sequenced Providencia plasmids [25-27] were present but undetected in the remaining sequences from this study, we constructed a BLAST database of all of the reads from the Roche/454 sequencing of each individual species and searched for reads matching each Providencia plasmid using BLAST+ (version 2.2.25). Four previously identified Providencia plasmids were used as query sequences: pDIJ09-518a [GenBank:HQ834472.1], pGHS09-09a [GenBank:HQ8 34473.1], pMR0211 [GenBank:JN687470.1], and R7K [Genbank:NC_010643.1].

\section{Identification of orthologs}

Orthologous genes were identified as shared among three different sets of bacteria: (1) the strains of $P$. sneebia, $P$. rettgeri, $P$. alcalifaciens, and $P$. burhodogranariea sequenced in this study; (2) the strains of $P$. sneebia, $P$. rettgeri, $P$. alcalifaciens, and $P$. burhodogranariea sequenced in this study plus the strains of $P$. rettgeri, $P$. alcalifaciens, $P$. stuartii, and $P$. rustigianii sequenced as part of the Human Microbiome Project [5]; (3) the strains of $P$. sneebia, $P$. rettgeri, $P$. alcalifaciens, and $P$. burhodogranariea sequenced in this study plus the strains of $P$. rettgeri, $P$. alcalifaciens, $P$. stuartii, and $P$. rustigianii sequenced as part of the Human Microbiome Project plus the outgroup Proteus mirabilis strain HI4320. Orthologous gene clusters were identified using OrthoMCL (version 2.0.2) [28]. BLAST results used within OrthoMCL were performed with an e-value cut off of $10^{-10}$. The output from OrthoMCL was parsed using custom Python scripts.

\section{Alignments of orthologs}

Orthologous gene clusters found among the strains sequenced in this study, those Providencia sequenced as part of the Human Microbiome Project, and Proteus mirabilis were aligned for phylogenetic analysis (see "Phylogenetic analysis" section below). Those orthologs of the strains sequenced in this study only were aligned for use in the recombination and positive selection analyses (see "Recombination analysis" and "Positive selection analysis" sections below). Only clusters with clear single gene orthology across each genome were retained. Alignments of the protein translation of the genes were done using ClustalW (version 2.1) [29] followed by back-translation to the nucleotide alignment using PAL2NAL (version 13) [30]. Alignments were visually inspected and poor alignments were removed as follows. We eliminated alignments where the difference in amino acid identity between the most-similar and least-similar 
pairs of species were greater than $60 \%$ out of concern that these might not be true orthologs. We also excluded alignments that had both an average protein identity that was less than $65 \%$ and a difference between the highest and lowest pair-wise protein identities greater than 35\%. Those alignments that had an average protein identity of less than $75 \%$ were examined by hand to ensure proper alignment.

\section{Phylogenetic analysis}

The alignments of all 1651 ortholog clusters that included all eight sequenced Providencia genomes and Proteus mirabilis were concatenated using FASconCAT (version 1) [31]. RAxML (version 7.2.8) [32] was used to construct the phylogenetic trees for the concatenation of all orthologous genes. Proteus mirabilis was set as an outgroup.

\section{Synteny and regional comparisons}

Synteny among genomes was examined using Mauve (version 2.3.1) [33], Artemis Comparison Tool (version 1) [34], and MUMmer. Comparisons of particular regions of the genomes were done using EasyFig (version 1.2) [35].

\section{Recombination analysis}

Evidence for recombination was examined by executing the programs GENECONV which implements the Sawyer method [36] and PhiPack [37]. GENECONV was run using the default settings, which estimates $p$-values on 10,000 permutations of each alignment. PhiPack runs 3 separate tests: Pairwise Homoplasy Index, Maximum $\chi^{2}$, and Neighbor Similarity Score. The Pairwise Homoplasy Index was calculated on a window size of 50 while Maximum $X^{2}$ was calculated on a window that is $2 / 3$ the size of the polymorphic sites. We did 1000 permutations in PhiPack to calculate each $p$-value. The $p$-values of all tests were corrected for multiple testing using the program Q-value [38] with a FDR of $10 \%$, acknowledging that the multiple tests conducted are highly intercorrelated and a stricter correction would therefore be overly conservative $[39,40]$.

\section{Positive selection analysis}

Positive selection analysis was done using PAML (version 4.4) [41] on the 1937 orthologous clusters found in the Providencia sequenced in this study. Site-model tests were implemented using codeml to compare model M8a $($ beta $+\omega=1)$ to M8 (beta+ $\omega)$ [41,42]. The log-likelihoods from each test were compared in a likelihood ratio test assuming a $X^{2}$ distribution of the test statistic. RAxML [32] was used to construct the phylogenetic trees for each ortholog cluster examined in this analysis. We corrected for multiple testing using a q-value cut off which was calculated with the program Q-value [38] using a FDR of $20 \%$, reflecting the conservative nature of the positive selection test $[39,40]$.

\section{Phage identification}

Phage genes were identified and classified using PHAST [43].

\section{Predicting the core genome size}

Custom scripts were written in Python to determine the number of orthologs for all combinations of 2, 3, 4, 5, 6, or 7 genomes of the eight sequenced Providencia genomes by parsing the OrthoMCL output described in the "Identification of orthologs" section.

\section{Results and discussion}

\section{Basic genome information}

The genomes of Providencia sneebia, Providencia rettgeri, Providencia alcalifaciens and Providencia burhodogranariea were sequenced in this study and assembled into $14,9,15$ and 8 contigs or scaffolds, respectively (Table 1 , Figures 1, 2, 3, and 4). The sequenced isolates were obtained from the hemolymph of wild Drosophila melanogaster and therefore will be referred to collectively as Dmel isolates in this paper. The summed contig or scaffold lengths of these assemblies vary from 4.5 Mb to $3.5 \mathrm{Mb}$, with $P$. burhodogranariea having the largest genome and P. sneebia having the smallest (Table 1). Because we know the sizes of the $P$. sneebia and $P$. rettgeri physical genomes from optical maps, we can discern that our $P$. sneebia assembly is missing approximately $300 \mathrm{~kb}$ of sequence and our $P$. rettgeri assembly is missing approximately $100 \mathrm{~kb}$ of sequences (Table 1). Based on the average gene size for each genome, we estimate that our annotated gene sets are missing roughly 275 out of 3750 for $P$. sneebia and 107 genes out of 4650 total for $P$. rettgeri (Table 1). Thus, we estimate that we have assembled approximately $93 \%$ of the $P$. sneebia coding genome and $98 \%$ of the $P$. rettgeri coding genome. Both $P$. alcalifaciens and $P$. burhodogranariea were sequenced with paired-end reads, resulting in scaffolds with sequence gaps of known sizes. These gaps can break up open reading frames, resulting in the absence of some genes from our inferred annotations. Since we did not optically map $P$. alcalifaciens or $P$. burhodogranariea, we do not know the precise sizes of their physical genomes. Because of the small assembly gaps, our annotations bear the caveat that a small number of genes may be inferred as absent when they are actually present in the physical genome.

\section{Plasmids}

We found 3 plasmids in $P$. sneebia, 1 in $P$. rettgeri, 1 in $P$. alcalifaciens and none in $P$. burhodogranariea (Table 1; Figures 1, 2, 3, and 4). We compared these 
Table 1 Basic genomic information of all four D. melanogaster isolated Providencia

\begin{tabular}{|c|c|c|c|c|c|c|c|c|c|}
\hline Species & Strain & $\mathrm{DSM}^{1}$ & & $\begin{array}{c}\text { Sequenced } \\
\text { size }^{2}\end{array}$ & $\begin{array}{l}\text { Physical } \\
\text { size }^{3}\end{array}$ & $\begin{array}{l}\text { \# of contigs } \\
\text { or scaffolds }\end{array}$ & $\begin{array}{c}\text { Average } \\
\text { GC } \%\end{array}$ & \# of genes & $\begin{array}{c}\text { Est. \# of } \\
\text { missing genes }\end{array}$ \\
\hline \multirow{4}{*}{$\begin{array}{l}\text { Providencia } \\
\text { sneebia }\end{array}$} & Type & 19967 & chromosome & $3.5 \mathrm{Mb}$ & $3.8 \mathrm{Mb}$ & 14 & 38.08 & 3482 & 275 \\
\hline & & & pPSN1 & $10787 \mathrm{bp}$ & $10787 \mathrm{bp}$ & 1 & 33.50 & 12 & 0 \\
\hline & & & pPSN2 & 7592 bp & 7592 bp & 1 & 35.05 & 12 & 0 \\
\hline & & & pPSN3 & $4321 \mathrm{bp}$ & 4321 bp & 1 & 31.50 & 4 & 0 \\
\hline \multirow{2}{*}{$\begin{array}{l}\text { Providencia } \\
\text { rettgeri }\end{array}$} & Dmel1 & - & chromosome & $4.2 \mathrm{Mb}$ & $4.3 \mathrm{Mb}$ & 9 & 40.20 & 4532 & 107 \\
\hline & & & pPRET1 & $5567 \mathrm{bp}$ & $5567 \mathrm{bp}$ & 1 & 40.81 & 6 & 0 \\
\hline \multirow{2}{*}{$\begin{array}{l}\text { Providencia } \\
\text { alcalifaciens }\end{array}$} & Dmel2 & - & chromosome & $4.2 \mathrm{Mb}$ & unk & 15 & 41.17 & 3900 & unk \\
\hline & & & pPALC1 & $14114 \mathrm{bp}$ & $14114 \mathrm{bp}$ & 1 & 37.57 & 17 & 0 \\
\hline $\begin{array}{l}\text { Providencia } \\
\text { burhodogranariea }\end{array}$ & Type & 19968 & chromosome & $4.5 \mathrm{Mb}$ & unk & 8 & 38.23 & 3985 & unk \\
\hline
\end{tabular}

${ }^{1}$ Strain number in DSM Culture Collection.

${ }^{2}$ Sum of the contigs or scaffolds lengths.

${ }^{3}$ Size of the physical chromosome as determined by optical maps. "unk" indicates unknown physical size.

${ }^{4}$ Estimated from the known length of sequence missing from these assemblies divided by the average gene length. "unk" indicates that the number of missing genes cannot be calculated due to an unknown physical size.

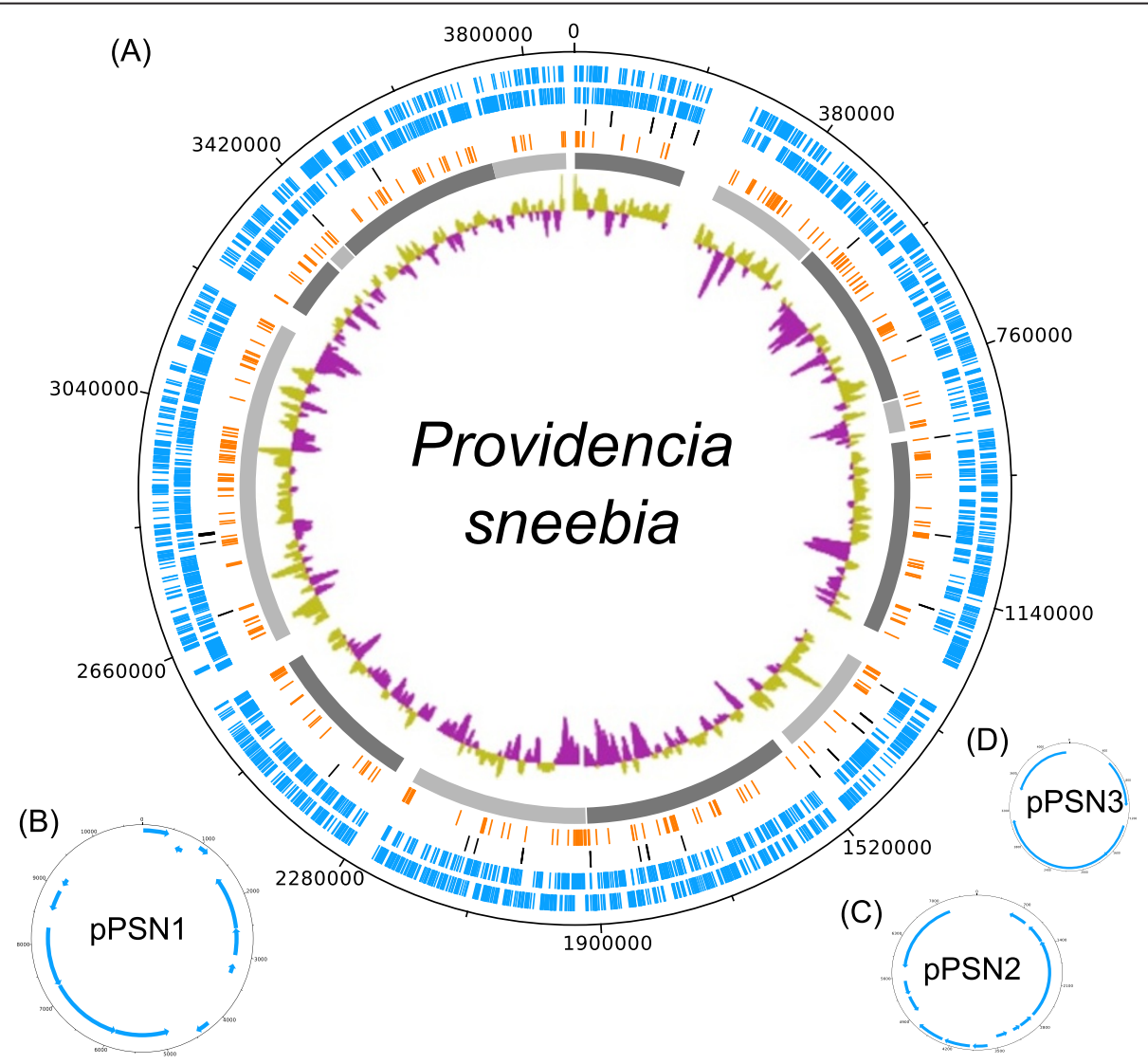

Figure 1 Circular maps of the Providencia sneebia genome and plasmids. (A) P. sneebia genome. The contigs are ordered and oriented as they are in the physical genome based on an optical map, including the sizes of the gaps between contigs. Rings from the outermost to the center: 1) genes on the forward strand (blue), 2) genes on the reverse strand (blue), 3) tRNA and rRNA genes (black), 4) genes unique to $P$. sneebia when comparing all 8 Dmel and HMP Providencia genomes (orange), 5) individual assembly contigs (alternating shades of grey), 6) GC skew. (B) pPSN1. (C) pPSN2. (D) pPSN3. All plasmids have the genes on the forward strand on the outermost ring and genes on the reverse strand on the inner ring. 


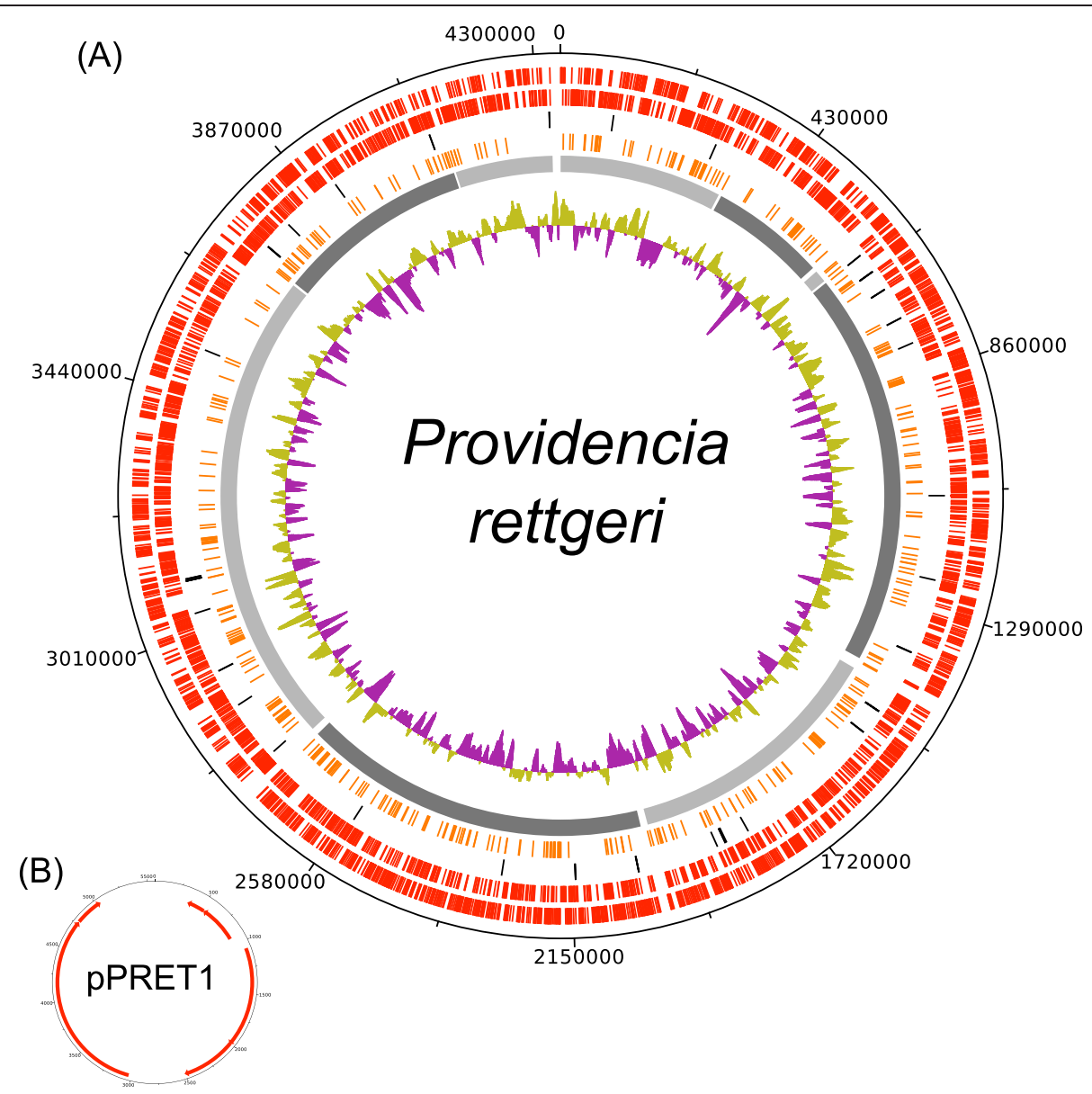

Figure 2 Circular maps of the Providencia rettgeri genome and plasmid. (A) P. rettgeri genome. The contigs are ordered and oriented as they are in the physical genome based on an optical map, including the sizes of the gaps between contigs. Rings from the outermost to the center: 1) genes on the forward strand (red), 2) genes on the reverse strand (red), 3) tRNA and rRNA genes (black), 4) genes unique to P. rettgeri when comparing all 8 Dmel and HMP Providencia genomes (orange), 5) individual assembly contigs (alternating shades of grey), 6) GC skew. (B) PPRET1. The plasmid has the genes on the forward strand on the outermost ring and genes on the reverse strand on the inner ring.

plasmids to each other and found them to have no similarity in gene content. We also checked whether any of these plasmids were undetected in the sequencing reads of the Dmel isolates other than the one that each plasmid was assembled from. We found that while some genes present on these plasmids were similar to paralogs on the chromosomes of other species, the complete plasmids were found only in the species from which they were initially recovered. Four plasmids have been isolated and sequenced by other groups studying other Providencia isolates [25-27], but we did not find any of these plasmids in the sequencing reads of our isolates.

We examined the plasmids for the presence of replication genes in order to determine their incompatibility group. The repA gene of PPALC1 has an IncFII domain and is most similar to one found in Yersinia pseudotuberculosis. This incompatibility group indicates that the plasmid has a host range limited to Enterobacteriaceae [44]. We found pPRET1 to have a Rop protein, which is similar to one found in Proteus vulgaris, suggesting that it uses an RNA based method of replication [45]. The replicase present on pPSN3 was found to contain a PriCT-1 domain, which has been found in a wide variety of bacteria, bacteriaphages and plasmids [46]. This replicase was similar to those found in numerous $E$. coli strains. We were unable to identify the replicase proteins for pPSN1 and pPSN2. This is most likely due to them using a replication method which is not well characterized. Plasmids previously isolated from different $P$. rettgeri isolates also do not carry obvious replicase genes [25], and pPSN1 and pPSN2 do not show similarity to these plasmids so it is likely that at least three different mechanisms are being used.

None of our novel Providencia plasmids contain genes with functional annotations that lead to a clear functional designation for the overall plasmid, such as "virulence" or "antibiotic resistance." Our findings indicate 


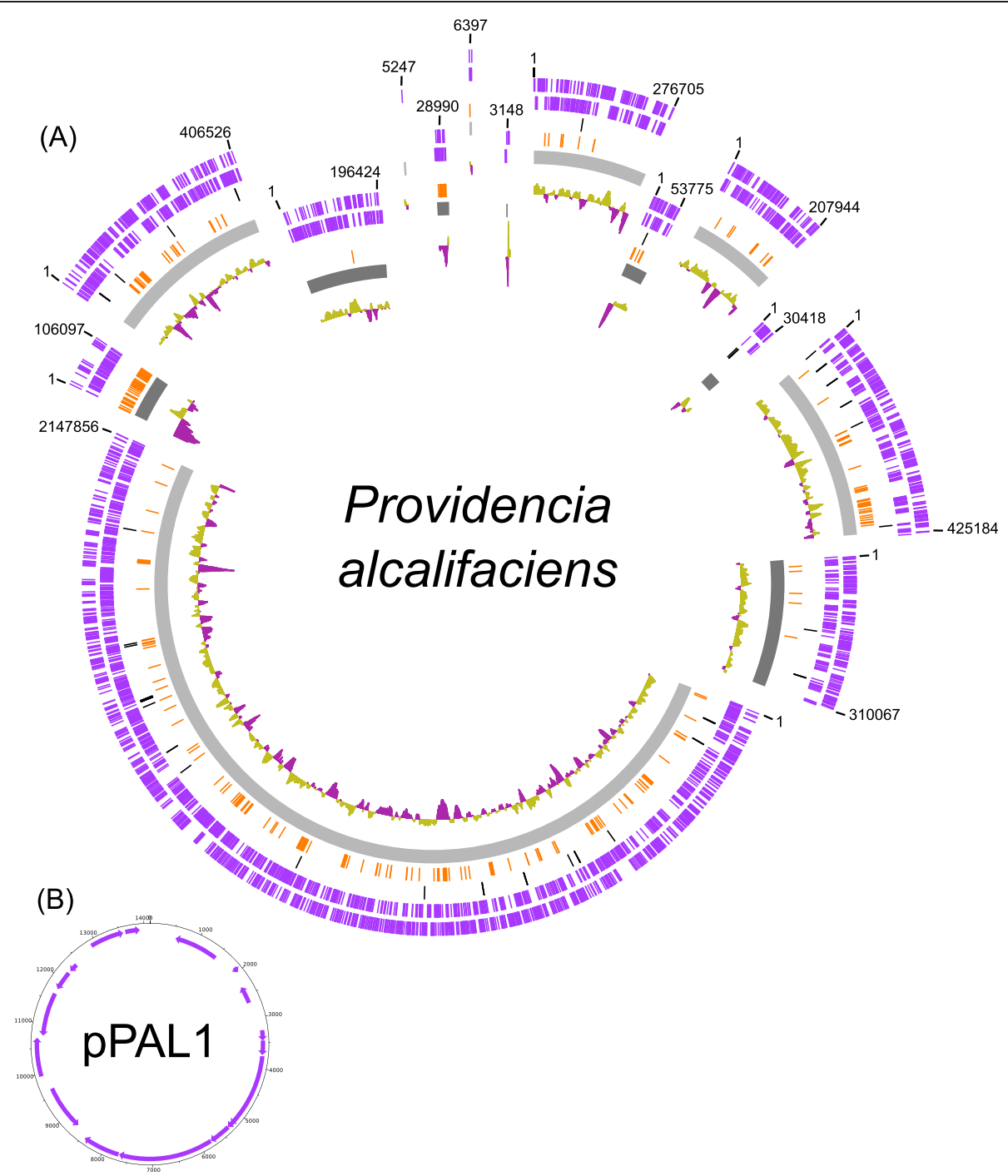

Figure 3 Maps of the Providencia alcalifaciens genome and plasmid. (A) P. alcalifaciens genome. The scaffolds are ordered and oriented for maximum synteny with $P$. rettgeri. The scaffolds are not positioned in a complete circle because the order and orientation of the scaffolds are not empirically known. The size of the gaps between scaffolds is unknown. Rings from the outermost to the center: 1) genes on the forward strand (purple), 2) genes on the reverse strand (purple), 3) tRNA and rRNA genes (black), 4) genes unique to P. alcalifaciens when comparing all 8 Dmel and HMP Providencia genomes (orange), 5) individual scaffolds (alternating shades of grey), 6) GC skew. (B) pPALC1. The plasmid has the genes on the forward strand on the outermost ring and genes on the reverse strand on the inner ring.

that plasmids found in Providencia vary considerably in their identity, conservation, replication methods and probable functions.

\section{Genomic synteny}

The optical maps of $P$. sneebia and $P$. rettgeri allowed us to order and orient the contigs as they are found in the physical chromosome for those two assemblies. The contigs of $P$. burhodogranariea and P. alcalifaciens were ordered and oriented so that they were as similar to the $P$. rettgeri and $P$. sneebia genomic orientations as possible, assuming the most parsimonious evolution of genome arrangements (Figure 5). It is in principle possible that any of the $P$. burhodogranariea and P. alcalifaciens contigs could be inverted or rearranged relative to their positions on our comparative syntenic plot, but only if the rearrangement breakpoints lie at contig breakpoints. While there are many small rearrangements found among the genomes, there are only two large inversions apparent across the four species. Both inversions are in $P$. sneebia relative to the other genomes (Figure 5). The ends of the largest $P$. sneebia inversion, which is about $800 \mathrm{~kb}$ in length, fall within single contigs of both $P$. burhodogranariea and $P$. alcalifaciens, supporting the hypothesis that the inversion is derived in and unique to P. sneebia. 


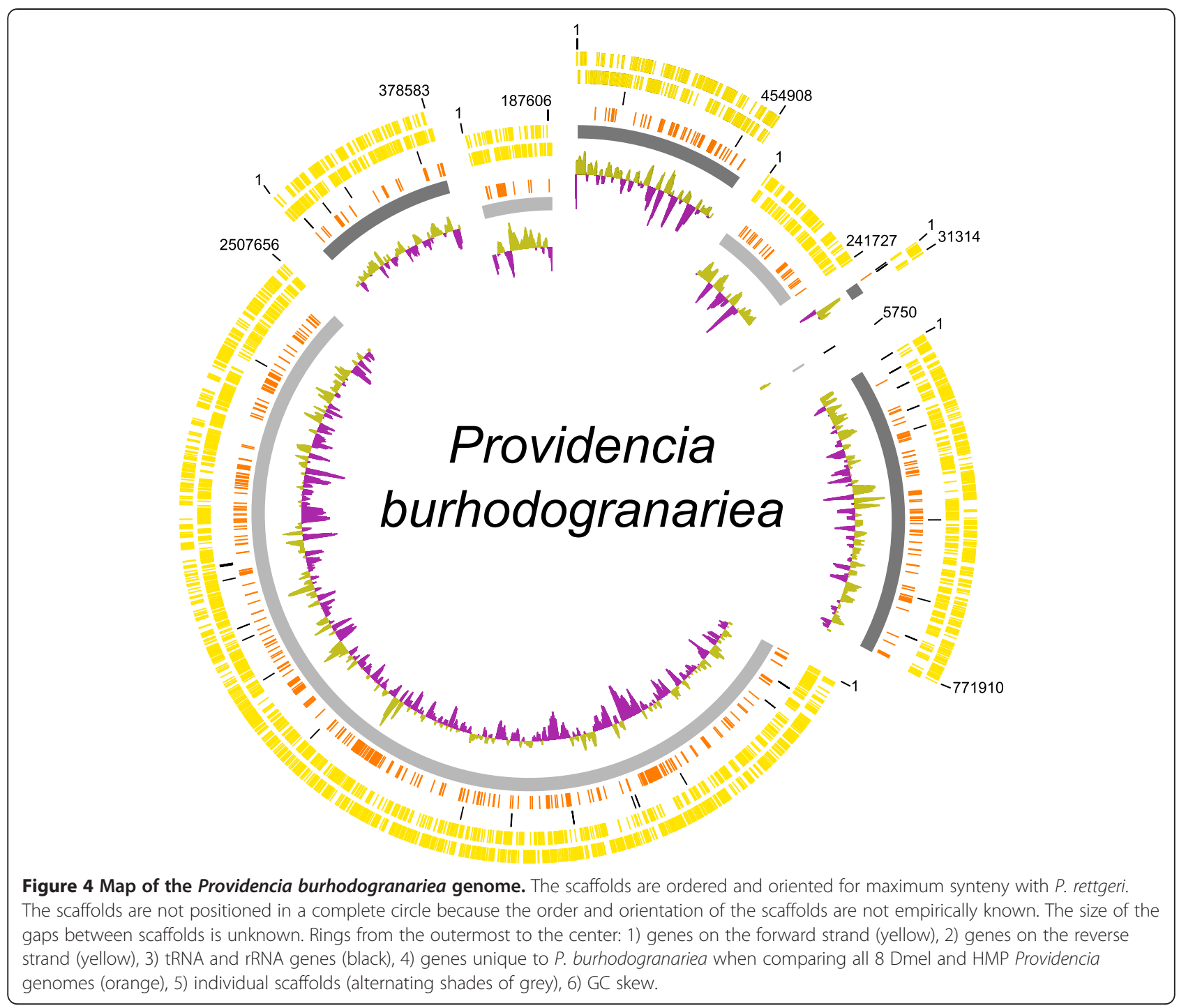

\section{Phylogeny}

We determined an overall phylogenetic relationship from a concatenated alignment of 1651 single-copy orthologs shared by all four Dmel Providencia sequenced here, rooted with Proteus mirabilis (Figure 6A). The phylogenetic tree indicates that $P$. sneebia and $P$. burhodogranariea share a common ancestor before either of them share a common ancestor with the $P$. rettgeri and $P$. alcalifaciens species pair (Figure 6A). This is consistent with the phylogenetic relationships proposed previously based on the 16S rRNA gene and five housekeeping genes [17].

\section{Orthologs and unique genes}

We wanted to know how much gene content is shared among the Dmel Providencia isolates so we used a BLAST-based method to find all orthologous gene clusters. There are a total of 3644 orthologous clusters containing between 10 and 2 genes, as well as one exceptional cluster containing 20 fimbrial-related usher genes with at least 3 genes originating from each genome. Fimbrial-related usher proteins chaperone other proteins to the bacterial cell surface to form a proteinaceous extension involved in surface adhesion [47]. We found that 3293 genes are present as single copies in each genome, or $90 \%$ of the total ortholog clusters. The majority of these clusters, 1983, comprise the core genome of these Providencia isolates (Figure 7), meaning that the genes are shared as single-copy orthologs across all four sequenced species. The core genome is $49-62 \%$ of the total genes in each genome, revealing that the species have a substantially homogeneous gene content. The next largest group of orthologous clusters is that which contains genes present in $P$. rettgeri, $P$. alcalifaciens, and $P$. burhodogranariea but absent from P. sneebia (Figure 7). This is consistent with these three genomes each being almost one megabase bigger than that of P. sneebia. Given that P. sneebia shares a 

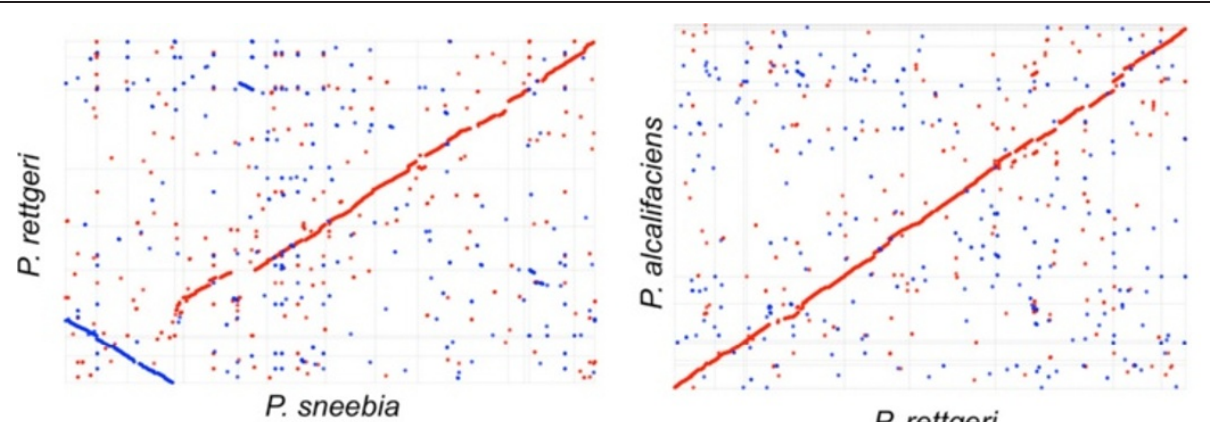

\section{P. rettgeri}


Figure 5 Alignments of the protein translations of the whole genomes of all four Providencia species isolated from D. melanogaster. The contigs of $P$. sneebia and $P$. rettgeri were ordered and oriented as they are in the physical genome based on optical maps made of each genome. $P$. alcalifaciens and $P$. burhodogranariea contigs were ordered and oriented for maximum synteny with $P$. rettgeri, therefore assuming parsimony in the number of genomic arrangements. Similarity was calculated using promer function in MUMmer [21]. Red dots represent similar sequence in the same orientation in each genome pair while blue indicates that the similarity is in the opposite orientations in the genome pairs.

common ancestor with $P$. burhodogranariea before either shares a common ancestor with the more distantly related $P$. rettgeri and $P$. alcalifaciens (Figure $6 \mathrm{~A}$ ), the absence of these genes in $P$. sneebia appears to reflect genome reduction in $P$. sneebia. To specifically examine putative gene loss, we determined the number of orthologous clusters that were missing a gene from only 1 of the 4 genomes (Figures $6 \mathrm{~B}$ and 7 ). While $P$. rettgeri, $P$. alcalifaciens, and $P$. burhodogranariea have between 74 and 89 genes that are apparently lost in their lineages, P. sneebia appears to have specifically lost 398 genes. As revealed in the analysis of genomic synteny above, differences in gene number and genome sizes generally are the result of small duplications, deletions, or insertions. In particular, the missing genes in $P$. sneebia do not result from large block deletions but instead arise from many small deletions eliminating individual genes distributed around the genome (Figure 5).

We found 137 orthologous clusters which contained paralogous duplications unique to a single genome. The majority of these clusters contain genes that are related to mobile elements or phages suggesting that there are families of transposons or phages that are specific to individual species. Most other clusters of species-specific paralog groups were annotated as hypothetical proteins.

We were able to determine genes unique to each genome by identifying those genes that were not assigned to any orthologous cluster (Figures $6 \mathrm{~B}$ and 7 ). The genomes varied in the absolute number of unique genes, with the smallest genome, that of $P$. sneebia, having the fewest. Despite their variation in number among the 




Proteus mirabilis

(B) Lineage Gene Loss or Gain

\begin{tabular}{|l|c|c|}
\cline { 2 - 3 } \multicolumn{1}{c|}{} & $\begin{array}{c}\text { Gene } \\
\text { Loss }\end{array}$ & $\begin{array}{c}\text { Gene } \\
\text { Gain }\end{array}$ \\
\hline P. sneebia Dmel & 398 & 494 \\
\hline P. burhodogranariea Dmel & 75 & 755 \\
\hline P. rettgeri Dmel & 74 & 800 \\
\hline P. alcalifaciens Dmel & 89 & 647 \\
\hline
\end{tabular}

(C) Core Genome Size

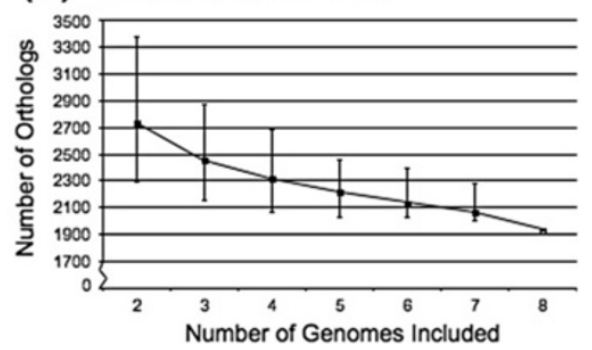

Figure 6 (A) Phylogenetic relationships of eight sequenced Providencia strains and the outgroup Proteus mirabilis. This phylogeny is constructed from a concatenation of 1651 orthologous genes shared by all nine genomes and was inferred using maximum likelihood methods within the program RAxML [32]. The Providencia isolated from D. melanogaster are shown in bold and color. The scale bar indicates number of substitutions per site. Each node of the tree is supported by a bootstrap value of 100. (B) Gene losses and gains along lineages leading to Providencia isolated from D. melanogaster. Numbers indicate the number of inferred gene gains and losses on each lineage for the four strains isolated from D. melanogaster. These numbers highlight that $P$. sneebia has experienced a much greater gene loss than the other species. (C) Core genome size when different numbers of genomes are included. The point indicates the average number of orthologs in each comparison while the error bars indicate the highest and lowest number of orthologs for all possible combinations of each number of genomes.

genomes, unique single-copy genes represent $15-19 \%$ of their total genome content for each species.

The genes unique to each bacterium were tested for enrichment of gene ontology (GO) terms compared to those genes found in either the Dmel Providencia core

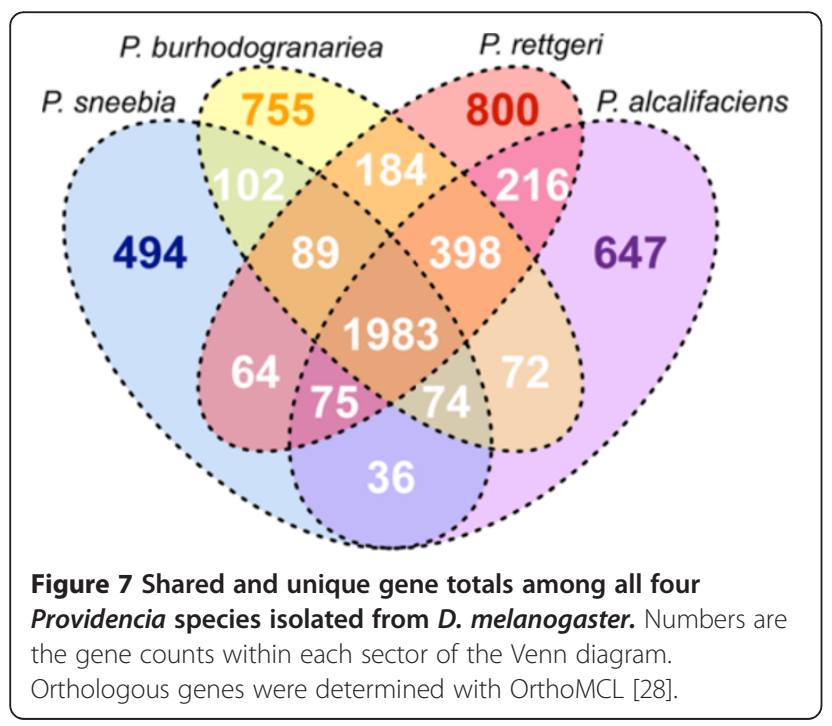

genome or the individual whole genome from which the unique genes were drawn (Figure 8). GO terms enriched among the genes unique to each species were often related to interactions with phage or bacteria, including genes encoding phage lysozymes, bacteriocins, and restriction enzymes. This strongly suggests that these Providencia have acquired or developed different ways to deal with varied genome parasites and competitor organisms. This may also imply variation in the phage or bacteria to which these Providencia are most often exposed.

Based on GO annotation, the genes unique to $P$. rettgeri are enriched for those involved in rhamnose metabolic process compared to both the core and whole genome. While the particular strain of $P$. rettgeri we sequenced has not been tested for its ability to metabolize rhamnose, the type strain of $P$. rettgeri has been shown to metabolize this sugar while the same strains of $P$. sneebia and $P$. burhodogranariea sequenced in this study were unable to [17]. The type strain of $P$. alcalifaciens has also been tested for its ability to metabolize rhamnose, but the data were ambiguous [17]. The collective data are suggestive that rhamnose 


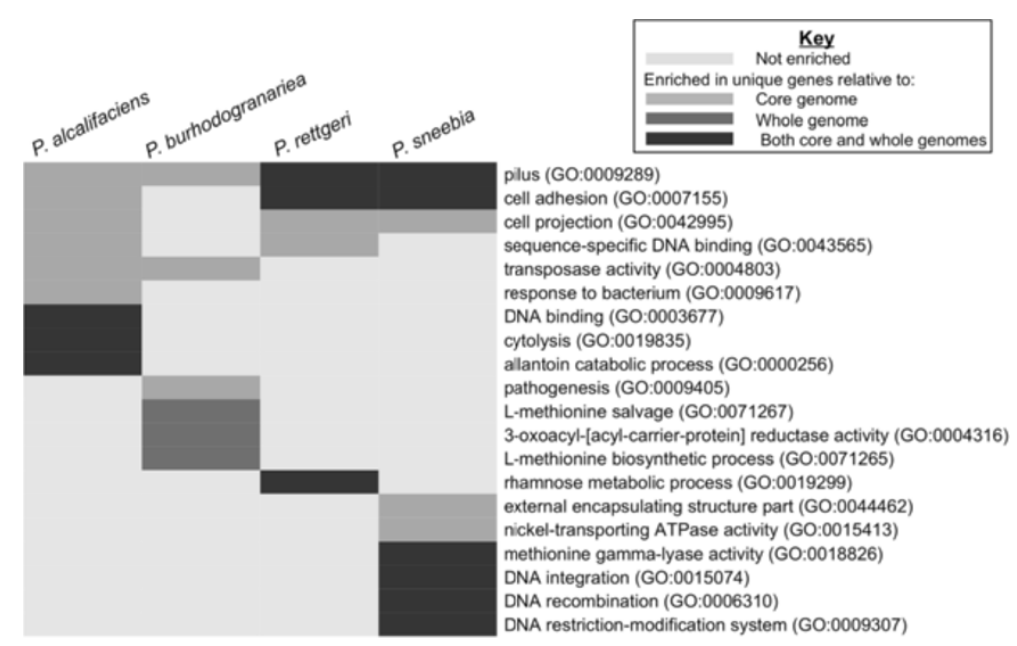

Figure $8 \mathrm{GO}$ terms enriched in the unique genes of each species compared to the full set of Providencia isolated from $D$. melanogaster. GO terms were assigned and calculation of enrichment was done using a Fisher's Exact Test using Blast2GO [24]. GO terms have been collapsed to only the most specific child term when multiple terms described the same group of genes.

metabolism may be unique to $P$. rettgeri among these strains of Providencia, although previous work has shown that not all strains of $P$. rettgeri are able to metabolize rhamnose [48].

All four species have genes with the GO term "pilus" significantly overrepresented in their unique genes compared to the core genome, although the absolute number of these genes varies for each genome (Figure 8). Pili are protein structures that extend from the surface of bacterial cells to allow the bacteria to adhere to substrates [47]. The majority of the unique genes given the pilus GO term are annotated as fimbrial proteins, which are the proteins that constitute the pilus structure [47]. The genic diversity indicates a high amount of variation in these fimbrial proteins. Pilus related proteins are often antigenic, so this variation in pilus protein could be a result of pressure to avoid host immune responses [49]. Alternatively, the distinction in fimbrial proteins could be due to variation among the species in adherence to specific surfaces [49]. As mentioned above, the largest orthologous gene cluster shared among the sequenced Providencia consisted of fimbrial-related usher proteins. These observations in combination show conservation of the genes which function to form the pilus but diversity of the genes encoding the proteins of the physical pilus structure itself.

\section{Recombination and positive selection}

Positive selection and recombination are two primary forces in bacterial evolution. Recombination rates have been found to vary widely in bacteria and it has been hypothesized that generalist bacteria or those in the process of adapting to new environments have higher rates of recombination [50]. These Providencia are closely related and were isolated from similar environments, so it is possible that there would have been opportunity for recombination among them. We examined 1937 orthologs in the core genome of the Dmel Providencia species for recombination, which is slightly reduced from the total 1983 core genome orthologs shown in Figure 7 due to the removal of comparatively poor sequence alignments (see Methods section "Alignments of orthologs"). Among the 1937 orthologs examined, 781 orthologous clusters that showed evidence for recombination. The genes belonging to clusters exhibiting recombination are evenly distributed around the physical genomes of each bacteria, and we do not find evidence for hotspots of recombination.

We used the program PAML [41] to test for evidence of positive selection in the Providencia core genome, excluding genes that showed evidence of recombination since these violate the assumptions of the tests in PAML [51]. This left 1156 orthologous clusters in the core genome shared by the four Dmel Providencia species isolates. We used PAML to compare the likelihood of a model which does not allow for positive selection, termed model M8a, to a model that does allow for selection at various sites along the gene, model M8 [41,42]. We found 21 genes that yielded nominal $p$-values of less than 0.05 , indicating that the model allowing for selection fit the data significantly better that the neutral model (Table 2). However, none of these 21 genes remained significant after application of a FDR of $20 \%$ [38]. Our selection test is extremely underpowered within Providencia given the small number of species examined and their close phylogenetic relationship to one another. We considered running the same site model tests on the four Dmel Providencia species plus 
Table 2 Orthologous gene clusters with evidence for positive selection

\begin{tabular}{|c|c|c|c|}
\hline Annotation & SEED Subsystem ${ }^{1}$ & $\mathrm{EC}^{2}$ & $p$-value \\
\hline homocysteine methyltransferase & methionine biosynthesis & 2.1 .1 .14 & 0.000496 \\
\hline xanthine/uracil/thiamine/ascorbate permease family protein & purine utilization & - & 0.002595 \\
\hline TolC precursor & multidrug efflux pumps & - & 0.003340 \\
\hline acetate permease ActP & acetogenesis from pyruvate & - & 0.003703 \\
\hline hypothetical protein with DUF177 & - & - & 0.007188 \\
\hline 2-octaprenyl-6-methoxyphenol hydroxylase & ubiquinone biosynthesis & 1.14.13.- & 0.009478 \\
\hline UDP-N-acetylglucosamine & - & 2.4.2.227 & 0.010464 \\
\hline D-tyrosyl-tRNA(Tyr) deacylase & stringent response & - & 0.014392 \\
\hline sulfate transport system permease protein CysT & cysteine biosynthesis & - & 0.014526 \\
\hline yihD & - & - & 0.015702 \\
\hline antibiotic biosynthesis monooxygenonase & - & - & 0.015830 \\
\hline 4-diphosphocytidyl-2-C-methyl-derythritol kinase & isoprenoid biosynthesis & 2.7.1.148 & 0.018713 \\
\hline Acyl-phosphate:glycerol-3-phosphate O-acyltransferase PIsY & $\begin{array}{l}\text { glycerolipid and glycerophospholipid } \\
\text { metabolism }\end{array}$ & - & 0.021835 \\
\hline dethiobiotin synthetase & biotin biosynthesis & 6.3.3.3 & 0.029052 \\
\hline LSU ribosomal protein L9p & ribosomal LSU & - & 0.029278 \\
\hline Ribonuclease $\mathrm{E}$ & ribosomal biogenesis, RNA processing \& & 3.1 .26 .12 & 0.030756 \\
\hline acyl carrier & $\begin{array}{l}\text { degradation protein glycerolipid and } \\
\text { glycerophospholipid metabolism }\end{array}$ & - & 0.031606 \\
\hline predicted Fe-S oxidoreductase & - & - & 0.041952 \\
\hline flagellar transcription activator FlhC & flagellum & - & 0.044270 \\
\hline magnesium transporter & - & - & 0.048181 \\
\hline
\end{tabular}

$P$-values were calculated using codeml within PAML [41] by comparing models M8a and M8 and are uncorrected for multiple testing.

${ }^{1}$ The subsystem and protein function designation were determined through annotation with RAST [23] with the exception of the proteins annotated as antibiotic biosynthesis monooxygenonase which was designated by Blast2GO [24].

${ }^{2}$ Enzyme Commission number.

Proteus mirabilis, but we there are too many synonymous changes on the lineage leading to Proteus mirabilis for the tests to be conducted appropriately. We present some genes that show nominal evidence for positive selection below, but stress that the selection results are provisional and further investigation into the biological function and adaptive significance of these genes is warranted.

One gene exhibiting evidence for positive selection is the TolC precursor $(p=0.003)$. The TolC gene has also been found to be under positive selection in E. coli [52]. This gene encodes an outer membrane protein that is part of a transporter system which transports toxins or antibiotics out of the cell $[53,54]$. It is possible that different proteins or varying amounts of proteins are transported by TolC in the various Providencia species, in which case selection may act on TolC to optimize interaction with different partners or vary secretion amounts.

Two different orthologous gene clusters showing weaker signal for positive selection were annotated as being involved in glycerolipid and glycerophospholipid metabolism $(p=0.022$ and $p=0.032)$. This subsystem is involved in making lipids that are transported to the bacterial cell surface. The signatures of positive selection suggest possible adaptation in lipid and protein structures on the surface of these Providencia species.

We found the protein FlhC to also show weak evidence for positive selection $(p=0.044)$. This protein forms a heterodimer with FlhD to become the master regulatory complex of flagellar protein production, and these proteins have also been shown to regulate the expression of many other genes, including virulence genes [55-57].

\section{Similarity of Dmel isolates to Providencia isolates from the human gut}

Four Providencia isolated from human feces have been sequenced as part of the Human Microbiome Project [5]. These included isolates of $P$. rettgeri and $P$. alcalifaciens as well as isolates of the species Providencia stuartii and Providencia rustigianii (Figure 6A). These isolates will be referred to as the HMP isolates, to distinguish them from the Dmel isolates sequenced in our study. We used the 1651 orthologous genes found in all eight sequenced Providencia and Proteus mirabilis to determine the phylogenic relationship of these bacteria. 
We found that $P$. stuartii shared its most recent common ancestor with $P$. burhodogranariea, while $P$. rustigianii and $P$. alcalifaciens share their most recent common ancestor (Figure 6A). This phylogenic analysis also indicates that the genes found in the core genome of the two isolates of $P$. alcalifaciens are more similar to one another than the two P. rettgeri isolates (Figure 6A).

We hypothesized that the four HMP isolates might have specialized genes to facilitate living in the human gut while the Dmel isolates would have genes enabling infection of $D$. melanogaster and other insects. To test this hypothesis, we extracted all orthologs of the eight genomes, yielding 4926 total ortholog clusters. Only 177 orthologous clusters, $3.5 \%$ of the total, contained no genes from any HMP isolates and were therefore specific to the Dmel isolates. None of these contained genes found in all four Dmel isolates, meaning there are no genes that are exclusive to and universal in these isolates. Similarly, only 354 , or $7.2 \%$ of the total ortholog clusters contain no genes from any Dmel isolate and therefore were exclusive to the HMP isolates. The majority of the HMP-specific ortholog clusters, 235 clusters, only contain two orthologous genes. Eleven of the HMP-specific ortholog clusters are found in all four of the isolates. Eight of these are assigned annotations that relate to phage activity and are physically colocalized in their respective genome. It is therefore unlikely that they are required for colonization of the human gut per se, but instead they probably reflect the shared phage pressure in the common environment. These isolates did not all originate from the same human, suggesting that the relevant phage may be pervasive in human guts. These phage genes were identified as belonging to Fels-2 in P. alcalifaciens HMP and the Myoviridae prophages PSP3 in P. stuartii HMP, $P$. rettgeri HMP, and P. rustigianii HMP. These two prophages are closely related to each other [58]. Of the 354 HMP isolate specific orthologs and paralogs, 69 of them are found only in P. stuartii. Most of these, 47, are annotated as hypothetical proteins. The total data indicate that there are no endogenous Providencia genes that are specific to and ubiquitous in either isolation environment we examined, but we do find evidence that the bacteria are exposed to different phages in the respective environments.

The core genome derived from all eight Providencia genome sequences contained 1925 genes, only very slightly fewer than the 1983 genes in the core genome of the Dmel Providencia isolates. This gives us added certainty that the core genome of Providencia as a whole is highly conserved. We estimate the asymptote of the core genome size for the genus Providencia as more genomes are sequenced will be around 1900 orthologs (Figure 6C).
The proportion of genes unique to any one of the HMP isolates is approximately the same as the unique gene complement in the Dmel strains. Unique genes represent $9 \%$ to $17 \%$ of the gene total for each of the isolates when all eight genomes are examined. Unsurprisingly, the HMP isolates of $P$. alcalifaciens and P. rettgeri share genes with only the Dmel isolates of these same species. Whereas $16 \%$ of the $P$. alcalifaciens Dmel genome consisted of unique genes when the Dmel isolates were considered alone, that value drops to $9 \%$ when the HMP isolates are also considered. The number of unique genes in P. rettgeri Dmel shows a similar decrease, from $19 \%$ of the total genes when Dmel isolates are considered in isolation to $10 \%$ after inclusion of the HMP isolates. However, these decreases in the count of unique genes are not only due to the addition of another isolate of the same species. Of the 800 genes initially considered unique to the Dmel isolate of $P$. rettgeri, 167 are found in the HMP isolates of P. stuartii, P. alcalifaciens, or $P$. rustigianii. Half of the decrease in apparently unique genes in P. alcalifaciens Dmel is due to orthologs in the HMP isolates of $P$. stuartii, $P$. rettgeri and $P$. rustigianii.

The unique, single copy genes for each of the eight genomes were assigned $\mathrm{GO}$ terms and then examined for GO term enrichment relative to either the whole genome or the core genome of all eight sequenced Providencia (Figure 9). Both the Dmel isolate of P. burhodogranariea and the HMP isolate of P. alcalifaciens had no GO terms enriched in their unique genes compared to either their respective whole genomes or the core genome. This suggests that the distinct genes acquired by these isolates have a wide variety of functions. There is also no shared enrichment for GO terms among all isolates originating from the human gut or among all those isolated from $D$. melanogaster, further emphasizing that there is no class of genes that tie the isolates together based on isolation environment. The unique genes of $P$. rustigianii HMP also are enriched in $\mathrm{GO}$ terms relating to the endoplasmic reticulum (ER) membrane compared to both the core and $P$. rustigianii HMP whole genome (Figure 9). These proteins each have a PGAP1-like domain, which is known to function in the ER, but since bacteria do not have an ER, they are unlikely to be functioning the same way in P. rustigianii. Although this domain is found in other bacteria, to our knowledge, no bacterial function has been determined for this domain.

GO categories related to transposons or transposition were enriched in several genomes, suggesting that the genomes have unique transposable elements (Figure 9). Additionally, $P$. rustigianii HMP unique genes have a number of GO terms related to viruses that are enriched over the core and whole genome (Figure 9). These genes are present in multiple locations throughout the genome and are either annotated as phage proteins or are 


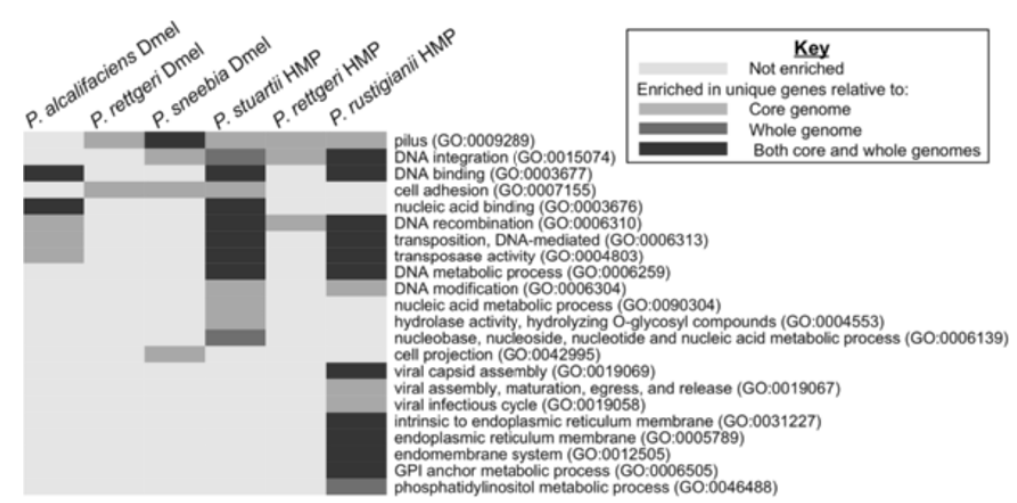

Figure $9 \mathrm{GO}$ terms enriched in the unique genes of each species when comparing the isolates collected from D. melanogaster (Dmel) to the isolates from the Human Microbiome Project (HMP). GO terms were assigned and calculation of enrichment was done using a Fisher's Exact Test using Blast2GO [24]. GO terms have been collapsed to only the most specific child term when multiple terms described the same group of genes. No GO terms were enriched in P. burhodogranariea Dmel or P. alcalifaciens HMP.

surrounded by prophage genes. This, again, emphasizes the variety of prophages and other mobile elements inserted in these genomes.

As seen when considering the Dmel genomes alone, the HMP genomes are also enriched for unique genes with the GO term "pilus" relative to the core genome (Figure 9). The enrichment in the GO term "pilus" disappears from the Dmel isolates of $P$. burhodogranariea and $P$. alcalifaciens after addition of the HMP isolates because some of the genes with this GO term previously considered "unique" are additionally found in the HMP isolates. P. sneebia and P. rettgeri retain enrichment of the pilus GO term as well as other GO terms related to adhesion in their set of unique genes relative to the core genome, emphasizing the uniqueness of their fimbrial proteins compared to the other Dmel strains and the HMP strains.

\section{Species-specific genes}

Two different isolates of both $P$. rettgeri and $P$. alcalifaciens have now been sequenced. One isolate of each species was sequenced from infected wild $D$. melanogaster (Dmel) while the other was isolated from human feces (HMP). There are 202 ortholog clusters that contain genes found only in the Dmel and HMP isolates of $P$. rettgeri, with six clusters containing more than two genes. The two isolates of $P$. alcalifaciens uniquely share 190 species-specific orthologous clusters. Unfortunately, most of these species-specific genes are annotated as hypothetical proteins so they do not lend any insight into biological distinction of these species from others in the Providencia genus. As described above for the individual isolates, genes annotated with the GO term "pilus" are enriched in genes specific to $P$. alcalifaciens relative to the Providencia core genome, and P. rettgeri is enriched for pilus genes and genes involved in rhamnose metabolic processes.

\section{Type 3 secretion systems}

A type 3 secretion system (T3SS) is a needle-like apparatus used by Gram-negative bacteria for injecting effector proteins into host cells [59]. The genes encoding the proteins of the needle machinery are physically clustered and may be acquired via horizontal gene transfer as a single "pathogenicity island". Transcription of the genes encoding the T3SS machinery and secretion of the effector proteins is triggered by external signals indicating that the bacteria is in the infection environment [60]. The functions of the translocated effector proteins vary greatly among bacteria, and include toxins that kill the host cells and proteins that manipulate host cell cytoskeletal activity or other cell biology to the advantage of the bacterium. Effector proteins are not necessarily encoded for within the same pathogenicity island as the genes encoding the T3SS needle apparatus, and may be acquired and evolve independently of the machinery [61].

All four Providencia sequenced in this study have at least one T3SS island (Figure 10A). P. sneebia Dmel, P. alcalifaciens Dmel, and P. rettgeri Dmel all have a similar T3SS island, which will be referred to as T3SS-1. These T3SS-1 islands are similar in sequence, gene content, gene orientation, and ATPase homology (Figure 10B). It is likely that this island was acquired prior to speciation of the sequenced Providencia as it is shared with Proteus mirabilis and the HMP Providencia isolates (Figure $10 \mathrm{~A}$ and $\mathrm{B}$ ) and is found in the same syntenic region in all three Dmel genomes, although this position lies inside the P. sneebia inversion. The genomic region surrounding the T3SS-1 island is much less conserved than the genes of the island itself. Even though $P$. sneebia, P. alcalifaciens, and $P$. rettgeri all share this T3SS, these bacteria have been shown to vary in virulence towards $D$. melanogaster [18]. Some work has been done to characterize 


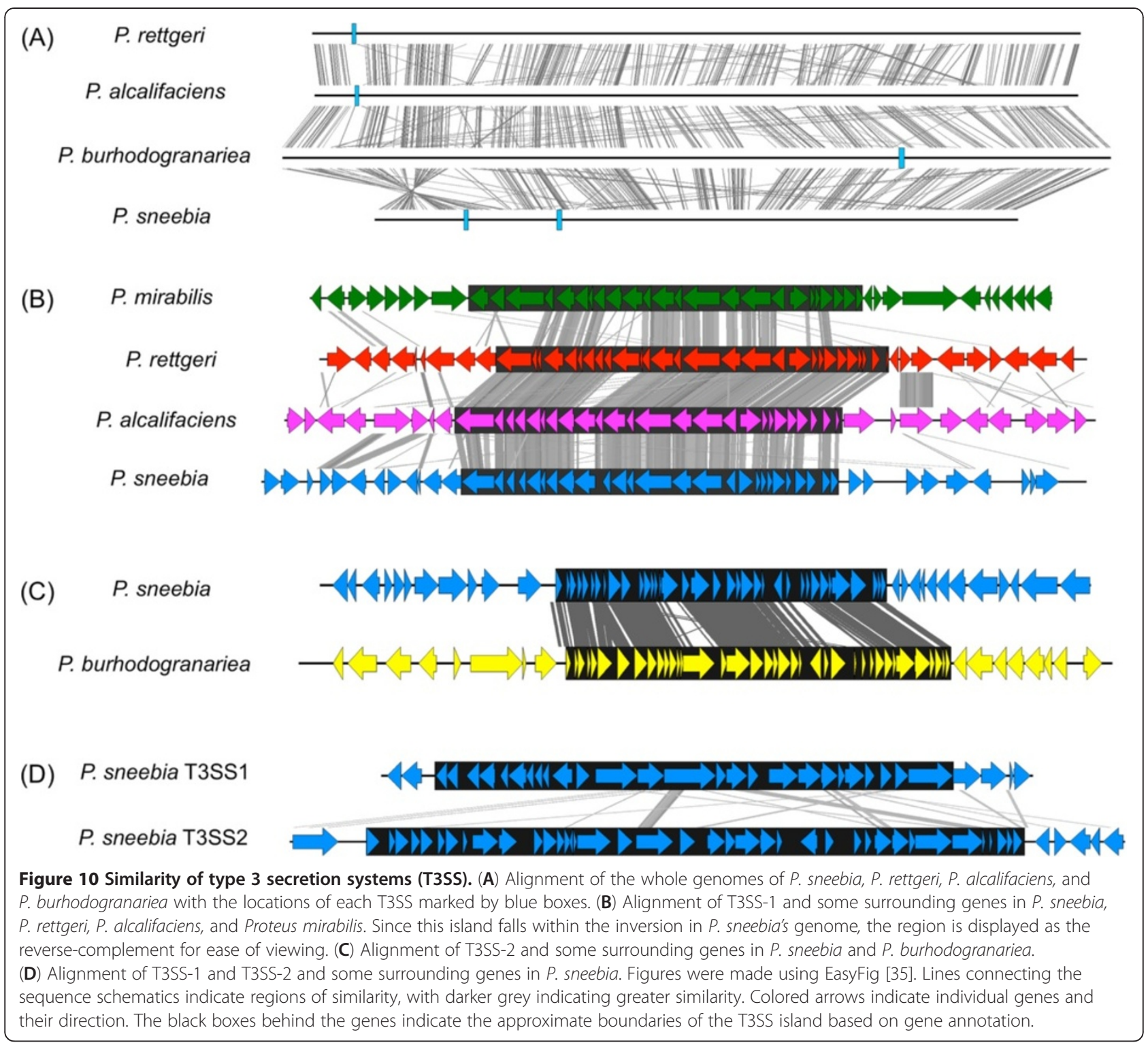

the T3SS-1 island of Proteus mirabilis during infection of the mouse ascending urinary tract, but disrupting the function of the secretion machinery had no effect on the bacteria's ability to colonize the mouse [62].

There is a second T3SS island present in the P. sneebia genome that is also found in P. burhodogranariea. We refer to this as T3SS-2. The T3SS-2 island is not found in any of the Providencia HMP isolates. Although T3SS-2 is not syntenically conserved in its genomic location between $P$. sneebia and P. burhodogranariea, the sequences and gene contents of the islands from the two species are much more similar to each other than they are to T3SS-1 of $P$. sneebia, $P$. alcalifaciens, and $P$. rettgeri, or even than the respective T3SS-1 islands are to each other (Figure 10). It would be equally parsimonious to conclude that the $P$. sneebia and $P$. burhodogranariea genomes have separately acquired T3SS-2 islands or to infer a single acquisition by their common ancestor followed by a subsequent relocation of the island in one of the genomes.

The ATPases of T3SS-1 and T3SS-2 belong to different families. The T3SS-1 ATPase belongs to the InvMxi-Spa ATPase family, which generally functions in cell invasion [61]. The ATPase of T3SS-2 belongs to the Ysc ATPase family, which is commonly found in extracellular pathogens [61]. Since P. sneebia carries both T3SS islands, it might be capable of functioning as both an extracellular pathogen and an intracellular one depending on infection context. However, the ATPase of T3SS-1 in our sequenced $P$. sneebia isolate contains a premature stop codon at codon 281 of the 420-codon gene, which likely abolishes the function of T3SS-1 in 
this isolate. We confirmed this stop codon by PCR and Sanger sequencing. We additionally sequenced the T3SS-1 ATPase from 8 additional isolates of P. sneebia originating from the hemolymph of wild caught $D$. melanogaster and found that they all have this stop codon (data not shown). While this does not mean all isolates of P. sneebia will have a stop codon in the ATPase of T3SS-1, it does suggest that this ATPase does not need to be functional for P. sneebia to cause an infection in $D$. melanogaster. None of the sequenced strains of $P$. sneebia, $P$. rettgeri and $P$. alcalifaciens showed evidence for the ability to intracellularly replicate in $D$. melanogaster cells in vitro, although $P$. alcalifaciens showed some evidence for being invasive and $P$. rettgeri and $P$. sneebia had evidence for resisting phagocytosis [18]. While a T3SS may be involved in these phenotypes for each species, it remains possible that these bacteria may have different intracellular replication or invasive phenotypes in $D$. melanogaster in vivo or in other hosts. Indeed, different strains of $P$. alcalifaciens have previously been shown to exhibit invasion of vertebrate cells $[63,64]$.

\section{Conclusions}

We sequenced and compared the draft genomes of four species of Providencia that were all isolated from the hemolymph of wild caught $D$. melanogaster $[17,18]$. We found the core genome of these isolates to be about $60 \%$ of the total coding content for each genome, even after inclusion of four isolates of Providencia originating from human feces. We found no genes that were specific to and universal in bacteria isolated either from D. melanogaster or from the human gut. Approximately $15 \%$ of each genome sequence consisted of genes unique to that isolate. These genes should explain variable phenotypes among the isolates, including metabolic differences [17] and variation in virulence towards D. melanogaster [18]. We found that each of these isolates has at least one type 3 secretion system. The unique genes of each genome are enriched for genes with the "pilus" GO term, suggesting variation in substrates that the bacteria adhere to. The T3SSs and the variety of adhesion molecules suggest that host cell contact is an important part of the virulence mechanisms for these Providencia.

\section{Additional file}

Additional file 1: Figure S1. Flow chart illustrating steps taken in the assembly of the $P$. sneebia and $P$. rettgeri genomes.

\section{Abbreviations}

ORF: Open reading frame; GO: Gene ontology; FDR: False discovery rate; Dmel: Bacteria isolated from hemolymph of D. melanogaster; HMP: Bacteria sequenced by Human Microbiome Project; T3SS: Type 3 secretion system.

\section{Competing interests}

The authors declare that they have no competing interests.

\section{Authors' contributions}

MRG and BPL conceived of the study, participated in its design, and drafted the manuscript. MRG preformed all computational work and PCRs. All authors read and approved the final manuscript.

\section{Acknowledgements}

We would like to thank Qi Sun for his help in assembling the genomes and finding orthologs, Jacob Crawford for his help using BWA during assemblies, Shannon Hedtke for her assistance in the phylogenetic analysis, Nathan Clark for his help with the positive selection analysis, and Henk den Bakker for assistance in submitting the genomes to GenBank. We would also like to thank Sarah Short, David Duneau, Jacob Crawford, Susan Rottschaefer, Rob Unckless and Virginia Howick for helpful discussions and comments on the manuscript. This work was supported by NIH grant Al083932 and a Priming Grant from the Cornell Center for Comparative and Population Genomics.

Received: 10 July 2012 Accepted: 5 November 2012

Published: 13 November 2012

\section{References}

1. Albert MJ, Alam K, Ansaruzzaman M, Islam MM, Rahman AS, Haider K, Bhuiyan NA, Nahar S, Ryan N, Montanaro J: Pathogenesis of Providencia alcalifaciens-induced diarrhea. Infect Immun 1992, 60:5017-5024.

2. Sobreira M, Leal NC, Magalhães M, Guth BE, Almeida AM: Molecular analysis of clinical isolates of Providencia alcalifaciens. J Med Microbiol 2001, 50:29-34.

3. Yoh M, Matsuyama J, Ohnishi M, Takagi K, Miyagi H, Mori K, Park K-S, Ono T, Honda T: Importance of Providencia species as a major cause of travellers' diarrhoea. J Med Microbio/ 2005, 54:1077-1082.

4. Sipahi OR, Bardak-Ozcem S, Ozgiray E, Aydemir S, Yurtseven T, Yamazhan T, Tasbakan M, Ulusoy S: Meningitis due to Providencia stuartii. J Clin Microbiol 2010, 48:4667-4668.

5. Peterson J, Garges S, Giovanni M, Mclnnes P, Wang L, Schloss JA, Bonazzi V, McEwen JE, Wetterstrand KA, Deal C, Baker CC, Di Francesco V, Howcroft TK, Karp RW, Lunsford RD, Wellington CR, Belachew T, Wright M, Giblin C, David H, Mills M, Salomon R, Mullins C, Akolkar B, Begg L, Davis C, Grandison L, Humble M, Khalsa J, Little AR, et al: The NIH human microbiome project. Genome Res 2009, 19:2317-2323.

6. Muller HE: Providencia friedericiana, a new species isolated from penguins. Int J Syst Bacteriol 1983, 33:709-715.

7. Foti M, Giacopello C, Bottari T, Fisichella V, Rinaldo D, Mammina C: Antibiotic resistance of gram negatives isolates from loggerhead sea turtles (Caretta caretta) in the Central Mediterranean Sea. Mar Pollut Bull 2009, 58:1363-1366.

8. Interaminense JA, Nascimento DCO, Ventura RF, Batista JEC, Souza MMC, Hazin FHV, Pontes-Filho NT, Lima-Filho JV: Recovery and screening for antibiotic susceptibility of potential bacterial pathogens from the oral cavity of shark species involved in attacks on humans in Recife, Brazil. J Med Microbiol 2010, 59:941-947.

9. Jackson TJ, Wang H, Nugent MJ, Griffin CT, Burnell AM, Dowds BCA: Isolation of insect pathogenic bacteria, Providencia rettgeri, from Heterorhabditis spp. J Appl Bacteriol 1995, 78:237.

10. Jho $Y$-S, Park D-H, Lee J-H, Cha S-Y, Han JS: Identification of bacteria from the oral cavity and cloaca of snakes imported from Vietnam. Lab Anim Res 2011, 27:213-217.

11. Ahmad A, Broce A, Zurek L: Evaluation of significance of bacteria in larval development of Cochliomyia macellaria (Diptera: Calliphoridae). J Med Entomol 2006, 43:1129-1133.

12. Mramba F, Broce A, Zurek L: Isolation of Enterobacter sakazakii from stable flies, Stomoxys calcitrans L. (Diptera: Muscidae). J Food Prot 2006, 69:671-673.

13. Kuzina LV, Peloquin JJ, Vacek DC, Miller TA: Isolation and identification of bacteria associated with adult laboratory Mexican fruit flies, Anastrepha Ludens (Diptera: Tephritidae). Curr Microbiol 2001, 42:290-294.

14. Gupta AK, Nayduch D, Verma P, Shah B, Ghate HV, Patole MS, Shouche YS: Phylogenetic characterization of bacteria in the gut of house flies (Musca domestica L.). FEMS Microbiol Ecol 2012, 79:581-593. 
15. Corby-Harris V, Pontaroli AC, Shimkets $L$, Bennetzen $J$, Habel KE, Promislow DEL: Geographical distribution and diversity of bacteria associated with natural populations of Drosophila melanogaster. Appl Environ Microbiol 2007, 73:3470-3479.

16. Chandler JA, Lang JM, Bhatnagar S, Eisen JA, Kopp A: Bacterial communities of diverse Drosophila species: ecological context of a host-microbe model system. PLoS Genet 2011, 7:e1002272.

17. Juneja P, Lazzaro BP: Providencia sneebia sp. nov. and Providencia burhodogranariea sp. nov., isolated from wild Drosophila melanogaster. Int J Syst Evol Microbiol 2009, 59:1108-1111.

18. Galac MR, Lazzaro BP: Comparative pathology of bacteria in the genus Providencia to a natural host, Drosophila melanogaster. Microbes Infect 2011, 13:673-683.

19. Shendure J, Ji H: Next-generation DNA sequencing. Nat Biotechnol 2008, 26:1135-1145.

20. Li H, Durbin R: Fast and accurate long-read alignment with burrowswheeler transform. Bioinformatics 2010, 26:589-595.

21. Kurtz S, Phillippy A, Delcher AL, Smoot M, Shumway M, Antonescu C, Salzberg SL: Versatile and open software for comparing large genomes. Genome Biol 2004, 5:R12.

22. Rozen S, Skaletsky H: Primer3 on the WWW for general users and for biologist programmers. Methods Mol Biol 2000, 132:365-386.

23. Aziz RK, Bartels D, Best AA, DeJongh M, Disz T, Edwards RA, Formsma K, Gerdes S, Glass EM, Kubal M, Meyer F, Olsen GJ, Olson R, Osterman AL, Overbeek RA, McNeil LK, Paarmann D, Paczian T, Parrello B, Pusch GD, Reich C, Stevens R, Vassieva O, Vonstein V, Wilke A, Zagnitko O: The RAST Server: rapid annotations using subsystems technology. BMC Genomics 2008, 9:75.

24. Conesa A, Götz S, García-Gómez JM, Terol J, Talón M, Robles M: Blast2GO: a universal tool for annotation, visualization and analysis in functional genomics research. Bioinformatics 2005, 21:3674-3676

25. Guillard T, Cambau E, Neuwirth C, Nenninger T, Mbadi A, Brasme L, VernetGarnier V, Bajolet O, de Champs C: Description of a 2,683-base-pair plasmid containing gnrD in two Providencia rettgeri isolates. Antimicrob Agents Chemother 2012, 56:565-568.

26. Mc Gann P, Hang J, Clifford RJ, Yang Y, Kwak YI, Kuschner RA, Lesho EP, Waterman PE: Complete sequence of a novel 178-kilobase plasmid carrying blaNDM-1 in a Providencia stuartii strain isolated in Afghanistan. Antimicrob Agents Chemother 2012, 56:1673-1679.

27. Revilla C, Garcillán-Barcia MP, Fernández-López R, Thomson NR, Sanders M, Cheung $M$, Thomas CM, de la Cruz F: Different pathways to acquiring resistance genes illustrated by the recent evolution of IncW plasmids. Antimicrob Agents Chemother 2008, 52:1472-1480.

28. Li L, Stoeckert CJ, Roos DS: OrthoMCL: identification of ortholog groups for eukaryotic genomes. Genome Res 2003, 13:2178-2189.

29. Larkin MA, Blackshields G, Brown NP, Chenna R, McGettigan PA, McWilliam $\mathrm{H}$, Valentin F, Wallace IM, Wilm A, Lopez R, Thompson JD, Gibson TJ, Higgins DG: Clustal W and Clustal X version 2.0. Bioinformatics 2007, 23:2947-2948

30. Suyama M, Torrents D, Bork P: PAL2NAL: robust conversion of protein sequence alignments into the corresponding codon alignments. Nucleic Acids Res 2006, 34:W609-W612.

31. Kück P, Meusemann K: FASconCAT: convenient handling of data matrices. Mol Phylogenet Evol 2010, 56:1115-1118.

32. Stamatakis A: RAxML-VI-HPC: maximum likelihood-based phylogenetic analyses with thousands of taxa and mixed models. Bioinformatics 2006 22:2688-2690

33. Darling AE, Mau B, Perna NT: ProgressiveMauve: multiple genome alignment with gene gain, loss and rearrangement. PLOS One 2010, 5:e11147.

34. Carver TJ, Rutherford KM, Berriman M, Rajandream M-A, Barrell BG, Parkhill J: ACT: the Artemis comparison tool. Bioinformatics 2005, 21:3422-3423.

35. Sullivan MJ, Petty NK, Beatson SA: Easyfig: a genome comparison visualizer. Bioinformatics 2011, 27:1009-1010.

36. Sawyer S: Statistical tests for detecting gene conversion. Mol Biol Evol 1989, 6:526-538

37. Bruen TC, Philippe $H$, Bryant D: A simple and robust statistical test for detecting the presence of recombination. Genetics 2006 172:2665-2681.

38. Storey JD, Tibshirani R: Statistical significance for genomewide studies. Proc Natl Acad Sci U S A 2003, 100:9440-9445.
39. Soyer Y, Orsi RH, Rodriguez-Rivera LD, Sun Q, Wiedmann M: Genome wide evolutionary analyses reveal serotype specific patterns of positive selection in selected Salmonella serotypes. BMC Evol Biol 2009, 9:264

40. Orsi RH, Sun $\mathrm{Q}$, Wiedmann M: Genome-wide analyses reveal lineage specific contributions of positive selection and recombination to the evolution of Listeria monocytogenes. BMC Evol Biol 2008, 8:233.

41. Yang Z: PAML 4: phylogenetic analysis by maximum likelihood. Mol Biol Evol 2007, 24:1586-1591.

42. Swanson WJ, Nielsen R, Yang Q: Pervasive adaptive evolution in mammalian fertilization proteins. Mol Biol Evol 2003, 20:18-20.

43. Zhou Y, Liang Y, Lynch KH, Dennis JJ, Wishart DS: PHAST: a fast phage search tool. Nucleic Acids Res 2011, 39:W347-W352.

44. Carattoli A: Resistance plasmid families in Enterobacteriaceae. Antimicrob Agents Chemother 2009, 53:2227-2238.

45. del Solar G, Giraldo R, Ruiz-Echevarría MJ, Espinosa M, Díaz-Orejas R: Replication and control of circular bacterial plasmids. Microbiol Mol Biol Rev 1998, 62:434-464.

46. Iyer LM, Koonin EV, Leipe DD, Aravind L: Origin and evolution of the archaeo-eukaryotic primase superfamily and related palm-domain proteins: structural insights and new members. Nucleic Acids Res 2005, 33:3875-3896

47. Kline KA, Dodson KW, Caparon MG, Hultgren SJ: A tale of two pili: assembly and function of pili in bacteria. Trends Microbio/ 2010, 18:224-232.

48. Penner JL, Hinton NA, Hennessy J: Biotypes of Proteus rettgeri. J Clin Microbiol 1975, 1:136-142.

49. Gerlach $R G$, Hensel M: Protein secretion systems and adhesins: the molecular armory of Gram-negative pathogens. Int J Med Microbi: IJMM 2007, 297:401-415.

50. Didelot $X$, Maiden MCJ: Impact of recombination on bacterial evolution. Trends Microbiol 2010, 18:315-322.

51. Anisimova M, Nielsen $R$, Yang Z: Effect of recombination on the accuracy of the likelihood method for detecting positive selection at amino acid sites. Genetics 2003, 164:1229-1236

52. Petersen L, Bollback JP, Dimmic M, Hubisz M, Nielsen R: Genes under positive selection in Escherichia coli. Genome Res 2007, 17:1336-1343.

53. Piddock LV: Multidrug-resistance efflux pumps - not just for resistance. Nat Rev Microbiol 2006, 4:629-636

54. Delepelaire P: Type I secretion in gram-negative bacteria. Biochim Biophys Acta 2004, 1694:149-161.

55. McCarter LL: Regulation of flagella. Curr Opin Microbiol 2006, 9:180-186.

56. Sule P, Horne SM, Logue CM, Prüss BM: Regulation of cell division, biofilm formation, and virulence by FlhC in Escherichia coli 0157:H7 grown on meat. Appl Environ Microbiol 2011, 77:3653-3662.

57. Givaudan A, Lanois A: FlhDC, the flagellar master operon of Xenorhabdus nematophilus: requirement for motility, lipolysis, extracellular hemolysis, and full virulence in insects. J Bacterio/ 2000, 102:107-115.

58. Lavigne R, Darius P, Summer EJ, Seto D, Mahadevan P, Nilsson AS, Ackermann HW, Kropinski AM: Classification of Myoviridae bacteriophages using protein sequence similarity. BMC Microbio/ 2009, 9:224

59. Galán JE, Wolf-Watz H: Protein delivery into eukaryotic cells by type III secretion machines. Nature 2006, 444:567-573.

60. Francis MS, Wolf-Watz H, Forsberg A: Regulation of type III secretion systems. Curr Opin Microbiol 2002, 5:166-172.

61. Troisfontaines P, Cornelis GR: Type III secretion: more systems than you think. Physiology (Bethesda) 2005, 20:326-339.

62. Pearson MM, Mobley HLT: The type III secretion system of Proteus mirabilis HI4320 does not contribute to virulence in the mouse model of ascending urinary tract infection. J Med Microbio/ 2007, 56:1277-1283.

63. Albert MJ, Ansaruzzaman M, Bhuiyan NA, Neogi PKB, Faruque ASG: Characteristics of invasion of HEp-2 cells by Providencia alcalifaciens. J Med Microbiol 1995, 42:186-190.

64. Janda JM, Abbott SL, Woodward D, Khashe S: Invasion of HEp-2 and other eukaryotic cell lines by Providenciae: further evidence supporting the role of Providencia alcalifaciens in bacterial gastroenteritis. Curr Microbiol 1998, 37:159-165.

doi:10.1186/1471-2164-13-612

Cite this article as: Galac and Lazzaro: Comparative genomics of bacteria in the genus Providencia isolated from wild Drosophila melanogaster. BMC Genomics 2012 13:612 